arterial access of roughly 40 minutes $(p=0.01)$ for patients having NCCT and CTA performed concurrently. As a result, downstream effects of the procedure demonstrated a reduction in time from presentation to aspiration thrombectomy initiation, from onset to aspiration, and from onset to final angiography (all $\mathrm{p}<0.05$ ). Notably, these patients demonstrated a higher rate of revascularization to mTICI $2 b-3(p=0.04)$.

Conclusion The effects on procedural and clinical outcome of having combined imaging efforts were less apparent in the entire cohort relative to the EVT cohort. These results suggest having concurrent NCCT and CTA imaging improves time from presentation to endovascular therapy, without significant delay to IV rtPA infusion. More patients were observed to achieve mTICI 2 b-3 if both imaging procedures were obtained in conjunction, possibly as a result of the reduction in time to endovascular intervention in this cohort. Further data from a larger sample size will help validate these findings.

Disclosures O. Zaidat: 6; C; Penumbra, Inc.. B. Mehta: None. A. Yoo: 1; C; National Institute of Health, Penumbra, Inc., Remedy Pharmaceuticals. R. von Kummer: 2; C; Penumbra, Inc. P. Khatri: 1; C; Penumbra, Inc. R. Gupta: 6; C; Penumbra, Inc. D. Lopes: 6; C; Penumbra, Inc. D. Frei: 3; C; Penumbra, Inc.. 6; C; Penumbra, Inc.. H. Shownkeen: None. D. Meyer: 5; C; Penumbra, Inc. V. Bach: 5; C; Penumbra, Inc. H. Buell: 5; C; Penumbra, Inc. S. Kuo: 5; C; Penumbra, Inc. A. Bose: 4; C; Penumbra, Inc.. 5; C; Penumbra, Inc. S. Sit: 4; C; Penumbra, Inc.. 5; C; Penumbra, Inc. J. Mocco: 1; C; Penumbra, Inc.

\section{0-004 ANALYSIS OF M2 OCCLUSIONS WITHIN TREVO ACUTE ISCHEMIC STROKE (TRACK) STENT-RETRIEVER THROMBECTOMY REGISTRY}

${ }^{1} \mathrm{~A}$ Castonguay, ${ }^{2} \mathrm{R}$ Nogueira, ${ }^{3} \mathrm{~J}$ English, ${ }^{4} \mathrm{~S}$ Satti, ${ }^{5} \mathrm{H}$ Farid, ${ }^{6} \mathrm{E}$ Veznedaroglu, ${ }^{6} \mathrm{M}$ Binning, ${ }^{7} \mathrm{~A}$ Puri, ${ }^{8} \mathrm{~N}$ Vora, ${ }^{8} \mathrm{R}$ Budzik, ${ }^{9} \mathrm{G}$ Dabus, ${ }^{9}$ I Linfante, ${ }^{10} \mathrm{~V}$ Janardhan, ${ }^{11} \mathrm{~A}$ Alshekhlee, ${ }^{12} \mathrm{M}$ Abraham, ${ }^{13} \mathrm{R}$ Edgell, ${ }^{14} \mathrm{M}$ Taqi, ${ }^{15} \mathrm{R}$ El Khoury, ${ }^{16} \mathrm{M}$ Mokin, ${ }^{16} \mathrm{M}$ Mokin, ${ }^{17} \mathrm{~A}$ Majjhoo, ${ }^{18} \mathrm{M}$ Kabbani, ${ }^{19} \mathrm{M}$ Froehler, ${ }^{20}$ I Finch, ${ }^{21} \mathrm{~S}$ Ansari, ${ }^{22} \mathrm{R}$ Novakovic, ${ }^{23} \mathrm{~T}$ Nguyen, ${ }^{1} \mathrm{O}$ Zaidat. ${ }^{1}$ St. Vincent Mercy Medical Center, Toledo, OH; ${ }^{2}$ Emory University School of Medicine, Atlanta, GA; ${ }^{3}$ California Pacific Medical Center, San Francisco, $C A_{;}{ }^{4}$ Christiana Care Health System, Newark, DE; ${ }^{5}$ St. Jude Medical Center, Fullerton, $C A ;{ }^{6}$ Drexel Neurosciences Institute, Philadelphia, PA; 'University of Massachusetts Medical School, Boston, MA; ${ }^{8}$ Riverside Radiology, Columbus, OH; ${ }^{9}$ Baptist Cardiac and Vascular Institute, Miami, FL; ${ }^{10}$ Texas Stroke Institute, Plano, TX; ${ }^{11}$ DePaul Stroke Center-SSM Neuroscience Institutes, St. Louis, MO; ${ }^{12}$ University of Kansas Medical Center, Kansas City, KS; ${ }^{13}$ St. Louis University, St. Louis, MO; ${ }^{14}$ Los Robles Hospital and Medical Center, Thousand Oaks, CA; ${ }^{15}$ Tulane University, New Orleans, LA; ${ }^{16}$ University of South Florida, Tampa, $F L_{;}{ }^{17}$ Wayne State School of Medicine, Detroit, MI; ${ }^{18}$ Gundersen Health System, La Crosse, WI; ${ }^{19}$ Vanderbilt University Medical Center, Nashville, TN; ${ }^{20}$ John Muir Health, Walnut Creek, CA; ${ }^{21}$ Northwestern University, Feinberg School of Medicine, Chicago, IL; ${ }^{22}$ UT Southwestern Medical Center, Dallas, TX; ${ }^{23}$ Boston Medical Center, Boston, MA

\subsection{6/neurintsurg-2016-012589.4}

Background and purpose Several recent randomized clinical trials have demonstrated the safety and efficacy of mechanical thrombectomy with stent retrievers for acute ischemic stroke patients with anterior circulation occlusions. However, these trials have limited enrollment of patients with M2 occlusions. Here, we sought to examine the clinical and angiographic outcomes of patients with M2 occlusions in the Trevo Acute Ischemic Stroke (TRACK) stent-retriever thrombectomy multicenter registry.
Methods Data from the investigator-initiated TRACK Registry (631 consecutive AIS patients, 23 clinical centers) was used to examine and compare demographic, clinical, and angiographic outcomes of patients with M1 versus M2 occlusions who were treated with TREVO as first treatment device.

Results Of the 631 patients enrolled in the TRACK registry, $84(13.3 \%)$ had M2 and 344 (54.5\%) had M1 occlusions. Mean age was similar between the M1 and M2 cohorts, $66.5 \pm 14.4$ and $64.7 \pm 3.8$ years $(\mathrm{p}=0.34)$, respectively. M2 patients had a lower median baseline NIHSS at presentation (14 (IQR 7-9) versus 18(IQR 14-22), p $\leq 0.0001)$. Time of onset to groin puncture $(347 \pm 237.4$ and $361 \pm 232.3$, $\mathrm{p}=0.63)$ and total procedural time (85.9 \pm 49.9 and $78.3 \pm 64.5, \mathrm{p}=0.4)$ was similar between the M1 and M2 cohorts. The number of passes with TREVO device was greater in the M1 cohort (Median, 2 (IQR 1-3) versus 1(IQR $1-2), p=0.01)$ as well as use of rescue therapy $(20.2 \%$ versus $9.8 \%, p=0.03)$. Patients with M2 occlusions achieved a higher rate of TICI 3 revascularization after the $1^{\text {st }}$ pass with TREVO device compared to those with M1 occlusions $55.8 \%$ versus $40.4 \%, \mathrm{p}=0.01)$. There was no significant difference in time to revascularization $(78.6 \pm 50.7$ versus $71.6 \pm 45.3$, $\mathrm{p}=0.2)$, revascularization success $(\geq$ TICI 2 b) $(80.5 \%$ versus $76.2 \%, \mathrm{p}=0.4)$, symptomatic intracranial hemorrhage $(5.6 \%$ versus $6.0 \%, \mathrm{p}=0.9), 90$ day modified Rankin Scale score $0-2(51.0 \%$ versus $57.4 \%, \mathrm{p}=0.35)$, or mortality $(16.1 \%$ versus $13.2 \%, \mathrm{p}=0.6$ ) between the M1 and M2 groups, respectively.

Conclusions Patients with M2 Occlusions are more likely to achieve complete recanalization from the first pass with Trevo stent retriever device than M1 occlusion. In addition, the M2 cohort had a numerically higher rate of good clinical outcome and less rate of mortality than M1 group. This substudy is limited by lack of a control M2 group without mechanical thrombectomy.

Disclosures A. Castonguay: None. R. Nogueira: None. J. English: None. S. Satti: None. H. Farid: None. E. Veznedaroglu: None. M. Binning: None. A. Puri: None. N. Vora: None. R. Budzik: None. G. Dabus: None. I. Linfante: None. V. Janardhan: None. A. Alshekhlee: None. M. Abraham: None. R. Edgell: None. M. Taqi: None. R. El Khoury: None. M. Mokin: None. M. Mokin: None. A. Majjhoo: None. M. Kabbani: None. M. Froehler: None. I. Finch: None. S. Ansari: None. R. Novakovic: None. T. Nguyen: None. O. Zaidat: None.

\section{0-005 INFLUENCE OF BALLOON, CONVENTIONAL, OR DISTAL CATHETERS ON ANGIOGRAPHIC AND TECHNICAL OUTCOMES IN STRATIS}

${ }^{1} \mathrm{O}$ Zaidat, ${ }^{2} \mathrm{D}$ Liebeskind, ${ }^{3} \mathrm{R}$ Jahan, ${ }^{4} \mathrm{M}$ Froehler, ${ }^{5} \mathrm{M}$ Aziz-Sultan, ${ }^{6} \mathrm{R}$ Klucznik, ${ }^{7} \mathrm{~J}$ Saver, ${ }^{8} \mathrm{D}$ Yavagal, ${ }^{9} \mathrm{~N}$ Mueller-Kronast. ${ }^{1}$ Neuroscience and Stroke Programs, St Vincent Mercy Medical Center, Toledo, $\mathrm{OH}^{2}{ }^{2}$ Neurovascular Imaging Research Core, University of California Los Angeles, Los Angeles, CA; ${ }^{3}$ Division of Interventional Neuroradiology, University of California Los Angeles, Los Angeles, CA; ${ }^{4}$ Cerebrovascular Program, Vanderbilt University Medical Center, Nashville, TN; ${ }^{5}$ Department of Neurosurgery, Brigham and Women's Hospital, Boston, MA; ${ }^{6}$ Department of Radiology, Methodist Hospital, Houston, TX; ${ }^{7}$ Department of Neurology and Comprehensive Stroke Center, University of California Los Angeles, Los Angeles, CA; ${ }^{8}$ Department of Neurology and Neurosurgery, University of Miami/Jackson Memorial Hospital, Miami, FL; ${ }^{9}$ Neurointervention Department, Delray Medical Center/Tenet South Florida, Delray Beach, FL 